\title{
Gente pasmada: febres contagiosas, apegadiças e sumárias na Braga Moderna
}

https://doi.org/10.21814/uminho.ed.23.10

\section{Maria Marta Lobo de Araújo}

Maria Marta Lobo de Araújo (ORCID: 0000-0002-6199-8033) é Professora Associada com Agregação do Departamento de História do Instituto de Ciências Sociais da Universidade do Minho e investigadora do centro Lab2PT da mesma Universidade. É doutora em História Moderna e Contemporânea pela Universidade do Minho, desenvolvendo investigação nos campos da História Social, com incidência particular na História das Misericórdias e da História Religiosa da Época Moderna. 


\section{INTRODUÇÃO}

As preocupações que hoje manifestamos com a saúde não são novas, embora se encontrem vestidas de outras roupagens. $\mathrm{Na}$ Idade Moderna, em tempo normal, manifestavam-se igualmente desejos de preservar a saúde, quer em termos teóricos, quer em termos práticos. Em alguns livros de viagem, mas também na correspondência particular são evidenciadas essas preocupações, pois era grande o medo da doença e ainda maior o da morte. Também alguns tratados sobre saúde refletem sobre estas questôes, constituindo o manual do médico Fernão Solis da Fonseca (1626), intitulado O Regimento para conservar a saúde e vida, um dos primeiros em Portugal que contem recomendaçôes para prevenir as doenças. No século XVIII, publicam-se alguns outros, contendo conselhos para a conservação da saúde das populações e as modalidades de curar achaques e moléstias. Destaca-se o nome de Francisco da Fonseca Henriques na publicação de várias obras e também António Ribeiro Sanches que, na sua obra Tratado da Conservação da saúde dos povos, publicada em 1756, sublinha os cuidados a ter com o corpo tendentes à manutenção da saúde. A saúde e a sua preservação ganharam importância no pensamento iluminista de setecentos, por serem entendidas como um dos pilares de prosperidade das sociedades (Abreu, 2010, p. 226). Simultaneamente, vários médicos e cirurgióes que escreveram sobre estas matérias utilizaram a língua vernácula e não o latim para tornar pública a sua mensagem a um maior número de pessoas (Abreu, 2019, p. 184-185).

Todos os que podiam procuravam levar uma vida saudável. Usufruir de bons ares, agasalhar-se do frio, descansar, evitar correntes de ar, entre outras, constituíam medidas preventivas de preservação da saúde, ao mesmo tempo que materializavam o temor que se tinha da doença. Este era tanto maior, quanto se sabia das dificuldades da medicina e da incapacidade de muitos acederem aos cuidados de saúde. Por outro lado, conhecia-se uma esperança média de vida muito baixa. Os serviços de saúde disponibilizados eram muito precários e as pestes regressavam com frequência ao quotidiano das populaçôes, marcando em alguns momentos o seu ritmo de vida, pelas alteraçóes profundas que nele provocavam. Pela importância de que se revestiam, as pestes constituíam-se um assunto de grande relevância pública. Era preciso combatê-las com todos os meios disponíveis. 
Falar de pestes na Idade Moderna é estudar núcleos urbanos de maior ou menor dimensão, onde a doença mais facilmente se instalava e os efeitos do contágio eram mais fortes. Embora não seja impossível estudá-las para o mundo rural, as fontes existentes são em maior quantidade para as cidades e vilas, pois era nestes espaços que se transformavam numa ameaça sempre latente, causando um desassossego constante na população e matando em elevado número. Era também nas cidades e vilas que as enfermidades e as pestes encontravam um terreno favorável para se instalarem e propagarem.

Neste trabalho analisamos as pestes em Braga na Idade Moderna, particularizando alguns momentos para os quais dispomos de maior informação. Única cidade do Minho no período em estudo, Braga era, como a maioria das cidades europeias, um núcleo urbano sujo, insalubre, que potenciava a doença, sempre à espreita. Conheceu várias pestes ao longo dos séculos em análise, assistindo a febres malignas que pasmavam a sua população devido ao forte contágio e às mortes que provocavam, mas também à impotência de as combater. Daremos visibilidade a esses momentos, demonstrando a forma como os poderes públicos atuavam na ordenação de medidas de higiene pública, mas igualmente o seu embate no hospital da cidade. Simultaneamente, analisaremos os efeitos na vida da comunidade e a maneira como ela entendia a doença, na ligação que estabelecia com o sagrado, pois esta era entendida como um castigo divino.

\section{AS DOENÇAS E AS PESTES NA IDADE MÉDIA}

A História está marcada por pestes e foram muitas as doenças e as pestes que grassaram em Portugal no período em análise. Algumas altamente contagiosas e penosas na Idade Média, conheceram um abrandamento na Idade Moderna, como aconteceu com a lepra e mesmo a peste bubónica. A Idade Moderna inicia-se sob o rescaldo de uma forte pandemia que dizimou uma parte muito substancial da sua população. A peste negra ou peste bubónica regressará por várias vezes à Europa e a Portugal durante os séculos XVI, XVII e XVIII, sem conhecer, todavia, os efeitos provocados em meados do século XIV.

Doença muito estigmatizante, a lepra levou os seus portadores a deslocarem-se para instituiçôes, que os próprios governavam, embora dentro delas pudessem também 
existir pessoas sem a doença, as chamadas leprosarias ou gafarias, onde se mantinham isolados e afastados dos sãos. Houve também os que nunca foram institucionalizados, andando pelas ruas ou permanecendo mais no resguardo das suas casas. As formas de gestão destas instituições assemelhavam-se, segundo Ângela Beirante, a uma confraria (Beirante, 2008, p. 235-251). Porém, o funcionamento destas instituiçôes variava de uma para as outras, existindo modelos diferenciados (Le Goff, 1985, p. 133). Situavam-se afastadas dos povoados, mas relativamente próximas, de maneira que os leprosos pudessem ser ajudados com esmolas (Beirante, 1994-1995, p. 213-228). A doença tocava todos os grupos sociais e na época não tinha cura, mantendo-se até à morte. Ali, como se estivessem no Purgatório, os doentes espiavam os seus pecados (Rawcliffe, 2001, p. 242). Procedia-se à separação dos doentes como medida preventiva para preservar a saúde dos restantes, uma vez que o contágio era forte (Tinoco, 2016, p. 33).

A gafaria era uma unidade orgânica, composta não somente pelas casas dos gafos, mas também pela igreja, estruturas anexas e ainda uma horta onde se cultivavam géneros para a subsistência dos internados. Algumas possuíam mais propriedades e outros cómodos para a vida diária (Oliveira, 1904, p. 533-535).

Apesar de ter sido muito problemática na Idade Média, a lepra conheceu um enorme retrocesso na Europa durante a Idade Moderna, de tal forma que a maioria das gafarias foi desmantelada, passando os seus edifícios e bens em Portugal, em vários casos, para as Misericórdias, confrarias de leigos criadas em 1498, com o surgimento da Misericórdia de Lisboa.

Braga teve na Idade Média várias gafarias, algumas situadas mais perto do centro urbano e outras um pouco mais afastadas. No início do século XVI são mencionadas duas, passando as rendas de uma que foi desmantelada, por ter poucos doentes, para o novo hospital de S. Marcos, fundado em 1508. A sua desativação acusava a desocupação em que se encontravam ou os poucos gafos que nelas permaneciam. Todavia, se esta era uma doença fortemente contagiosa, em desaceleração, outras surgem muito contagiosas e a necessitarem de tratamento. Referimo-nos à sífilis também designada por "boubas” e em algumas regiões de Portugal por “males”. A sífilis chegou à Europa no século XV e tornou-se um verdadeiro flagelo, por infetar muita gente, com incidência particular em vários grupos sociais e no Exército. Toda a população estava sujeita a 
contraí-la, mesmo as crianças. Muito estigmatizante por estar associada aos maus costumes e a relações sexuais não consentidas pela igreja católica (Arrizabalaga, 1995-1996, p. 125-142), não tinha cura e era apenas melhorada através de tratamentos. Perante um volume crescente de infetados, fundaram-se hospitais apenas para os seus portadores, mas em número muito limitado. Nas regióes onde estes não existiam, em Portugal os doentes eram tratados nos hospitais comuns, fazendo-se uma separação rigorosa dos restantes internados por causa do contágio.

Os tratamentos ocorriam duas vezes no ano, na Primavera e no início do Outono por serem ocasióes em que as temperaturas eram moderadas, permitindo aos doentes aguentar os suadouros a que eram sujeitos e não sendo submetidos a correntes de ar. Para além de suadouros, os infetados eram também tratados à base de unções mercuriais seguindo-se os conselhos dos manuais da época (Arrais, 1633). A arquitetura das enfermarias dos doentes devia obedecer a formas de isolamento, para facilitar os efeitos do tratamento (Jutte, 1996, p. 97-115).

O único hospital que tratava das boubas na diocese de Braga era o de S. Marcos, que recebia doentes de toda a sua vasta região, obrigando-o a um programa intenso de tratamento, nos períodos acima referidos. Dispunha de duas enfermarias para o fazer, conhecendo ao longo do século XVII uma enorme procura destes serviços. Situadas no rés-do-chão, longe das restantes que ficavam no primeiro andar, estas enfermarias obedeciam também a um funcionamento particular para evitar que o contágio da doença se propagasse para os outros internados e cuidadores. Roupa, utensílios alimentares e outros eram cuidadosamente separados durante o período de tratamento, que não ultrapassava as duas semanas. Como a procura disparou em seiscentos, o hospital teve necessidade de abrir várias curas durante a Primavera e no começo do Outono, procurando responder às necessidades conhecidas, uma vez que sem cura muitos doentes tratados num ano, eram reinternados no ano seguinte.

Para além das doenças referidas, na Idade Moderna, o tifo, a febre-amarela, a varíola, a tuberculose, a malária, o sarampo e a peste bubónica fazem parte do quotidiano das populaçóes, provocando graves epidemias, alterando significativamente a vida social e económica das populaçôes, causando muito medo e colocando a morte na centralidade da vida. Porém, muitas outras doenças do foro respiratório ou intestinal, por 
exemplo, atacavam as populações. Mas havia ainda sérios problemas de sarna e tinha, presentes nos grupos sociais mais débeis e também no Exército.

Surtos destas doenças ocorreram em várias partes da Europa e vindas deste continente, do Novo Mundo ou do Norte de África, chegavam a Portugal por mar e por terra, matando, agravando as desigualdades sociais e provocando grandes perturbações na vida das comunidades. O século XVI assistiu a vários surtos de peste nas primeiras décadas e na segunda metade conheceu a grande peste de 1569 em Lisboa, que matou uma parte substancial da sua população. Foi sentida em diversas regióes de Portugal, principalmente no Alentejo, Beiras e Algarve, mas também no Minho e Douro. Outras se lhe seguiram, enchendo de mortes os anos de 1579-80 e 1599. Foram tempos de muitas doenças, de fomes e de grande deslocamento de populaçóes pobres. Fugindo das localidades de origem à procura de melhores condições de vida, os pobres deambulavam de terra em terra e acorriam às grandes cidades à procura de uma esmola mais avantajada, embora quase sempre nelas encontrassem muitas dificuldades, por falta de alimentos e subida dos seus preços, o que os levava à desnutrição e à morte. Corpos famélicos contraíam mais facilmente a doença, por falta de defesas e de higiene corporal e pública.

Estas vagas de doenças permaneceram em seiscentos e setecentos, sendo em vários momentos agravadas pelas guerras sentidas nas duas centúrias, nomeadamente a guerra da Restauração, com uma parte desenrolada ainda no quadro da guerra dos 30 Anos, a guerra da Sucessão de Espanha e da guerra dos Sete Anos. No final do século XVIII, o quadro político militar ameaçou uma vez mais a Península Ibérica, com o envolvimento militar de Portugal. À doença juntava-se a destruição da guerra e a subida do preço do pão, principal alimento das populaçóes. Instalada a doença, aparecia o medo e a confusão de sentimentos perante a inevitabilidade da morte. A ineficácia do sistema público de saúde aproximava a morte e colocava as pessoas dependentes da crença, porque a morte era presença habitual. Embora o século XVIII traga novidades no que toca à saúde pública com o surgimento das primeiras vacinas, o certo é que a imunidade continuava a ser o meio mais seguro de não se ser contaminado. Contrair a doença significava no tempo em estudo a proximidade da morte, não de uma pessoa por casa, mas, por vezes, de todo o agregado familiar. 
Esta mortalidade excecional encontra reflexo não somente nas memórias escritas deixadas, por exemplo, nos livros de defuntos das paróquias e dos hospitais, mas também nos livros de memórias ou nas descrições das terras, como na pintura. Ex-votos e outros quadros materializam as imagens da doença e da morte, avivando as cores da negritude que o decesso arrasta. A análise de alguma pintura da Idade Moderna ajuda a compreender o fenómeno das pestes e da morte, destacando cenas de um quotidiano marcado pelo medo, pelo contágio e pela morte. É possível ainda estudar através dela algumas das doenças mais correntes no período em questão, por constituírem algumas das doenças mais temidas, por não terem cura e pela enorme facilidade com que se transmitiam. Como fontes privilegiadas para o estudo das pestes mencionam-se igualmente os livros de atas de vereação, por ser neles que se escreveram as medidas de combate às doenças e de promoção da saúde pública e os livros de atas, de doentes e morte dos hospitais.

\section{AS PESTES NA BRAGA MODERNA}

Braga como outras cidades replicava as doenças que chegavam e conheceu momentos muito difíceis. Em 1635, Portugal viveu uma situação política e económica complicada. A política dos Habsburgo, aplicada pela mão do conde duque de Olivares, causava muitos estragos nas populações que viam o seu quotidiano marcado por grande precariedade, com um enorme aumento de impostos e com a leva de soldados para combater em várias regiões do império espanhol, envolvido na guerra dos 30 Anos e ainda com problemas internos na Catalunha e na Biscaia. Acresce a este panorama um enorme desencanto com a política seguida, materializada em várias revoltas que se desencadearam um pouco por todo o lado (Oliveira, 2015, p. 1401-1421). Para além destes problemas, a peste tinha chegado à cidade.

Em tempos de epidemias e pestes, a preocupação com a morte sem data marcada levava à redação de testamentos, estabelecendo últimas vontades e preparando uma boa morte.

O surto de varíola que assolou a cidade marcou presença noutras localidades portuguesas estendendo-se em termos temporais até ao ano seguinte. Este tempo 
conturbado materializou-se em vários setores da vida das populações: sanitários, económicos, políticos e sociais. Massacrado pelo elevado número de impostos, opondo-se à política unionista do Conde Duque de Olivares, o povo manifestou-se sob a forma de motins em várias cidades e vilas do reino, ao longo de toda esta década, ao mesmo tempo que aumentavam as dificuldades de vida do mundo dos pobres.

Perante a notícia de que existia numa localidade perto uma peste, o poder local nomeava o guarda-mor da saúde, que atuava de forma coordenada com o poder central de onde saíam as principais orientações (Abreu, 2014, p. 63). Eram, porém os Municípios que as acionavam nas respetivas localidades. Após a nomeação do guarda-mor da saúde, a Câmara de Braga tomou várias medidas de higiene, procurando minimizar os efeitos da doença. Mandou limpar as frontarias das casas e proibiu o lançamento de lixo para as vias públicas, ao mesmo tempo que interditou a circulação de porcos nas ruas e condenou os infratores ao pagamento de multas e até mesmo, em algumas circunstâncias, a penas de cadeia. Este carácter punitivo para os infratores evidencia a corresponsabilização que lhes era atribuída por colocarem em perigo toda a comunidade. As cidades europeias de Idade Moderna eram locais sujos, onde imperava a insalubridade. Havia também animais mortos nas vias públicas, muitas vezes em putrefação, causando mau odor e polarizando as doenças. A limpeza era pouca e as medidas de higiene eram repetidas sempre que se instalava a peste, mas duravam apenas o tempo em que a localidade estivesse debaixo da sua ameaça. Também o facto de ser necessário repeti-las sempre que a doença se instalava demonstra como não eram tidas em consideração, nem cumpridas. Mas se isto se verificava, constata-se também a reclamação de alguns moradores contra a existência de resíduos às portas de particulares e nas vias públicas, contra os cheiros nauseabundos que se faziam sentir.

Os despejos de detritos nas vias públicas assumiam elevada preocupação junto das autoridades municipais, devido à questão sanitária (Pardal, 2007, p. 49). As cidades eram centros de comércio, por onde circulavam mercadores e pessoas à procura de produtos, mas eram também passagem ou local de receção de peregrinos, para além de serem aglomerados populacionais, compostos por ruas estreitas, algumas com pouca luz, mal arejadas, quase sempre sujas, malcheirosas, várias sem pavimentação e com animais em trânsito. Porcos, cães, gatos e outros animais, nomeadamente de capoeira, 
vagueavam pelas artérias da cidade, deixando dejetos. Mas as imundices podiam ter outras características: lixo doméstico, resultante das atividades económicas, como era o caso dos açougues e outras e ainda águas mal paradas, como se verificava frequentemente em poços ou fontes (Braga, 2001, p. 119) e mesmo nas praças e calçadas, constituindo focos contaminantes e ameaçadores. A proliferação de insetos prejudicava a vida das comunidades e piolhos, pulgas e ratos conviviam com as populações em locais insalubres e pobres, sendo através deles que algumas doenças se transmitiam. Estes agentes de contágio conviviam com as populações, principalmente nos locais mais humildes, constituindo permanentes focos perigosos para a saúde pública. Como as pessoas estavam familiarizadas com os insetos não suspeitavam dos males que eles provocavam.

A limpeza pública era muito deficiente, como era a do corpo. A presença de parasitas era frequente não somente nos corpos, mas também na roupa pessoal, de cama e nos enxergões. E se os percevejos se reproduziam principalmente no tempo quente do Verão, as pulgas e os piolhos estavam presentes em qualquer altura do ano. Era ainda a falta de limpeza corporal que potenciava o surgimento de tinha, tão frequente nas populações pobres, assim como nos corpos do Exército. Estas condições prejudicavam principalmente os pobres, pois a falta de uma alimentação condigna e as más condições de habitação contribuíam para o alastramento da doença e para a subida da mortalidade (Carmona García, 2000, p. 44). Sabe-se pouco sobre a higiene corporal dos enfermos, embora seja conhecido que tomavam banho quando eram internados, altura em que trocavam a sua roupa por uma camisa fornecida pelo hospital e que em Braga, em 1683, lhes era disponibilizada uma infusa e um prato para lavarem as mãos antes de tomarem as refeições (Araújo, 2014, p. 60). É ainda conhecido que a higiene do corpo na Idade Moderna se restringia à lavagem das partes que eram visíveis, nomeadamente a cara e as mãos, mudando-se apenas a camisa, isto é, a peça que estava mais em contacto com a pele, por se acreditar que ela reunia todas as impurezas segregadas pelo organismo.

Para além das medidas enunciadas, os poderes locais podiam acionar outras ações igualmente tendentes a diminuir o contágio: restrição do movimento das populações e à circulação de bens; vistoria de animais, limpeza das ruas, onde se podiam queimar ervas cheirosas e fazer fogueiras, proibição temporária da realização de feiras, romarias e outras festividades, como as procissões e, nos casos mais graves, criar 
cordóes sanitários, impedindo a entrada de gentes nas vilas e cidades, que se mandavam fechadas, no caso de existirem muralhas. Encerravam-se as portas, mas também os postigos, passando apenas os que tinham autorização para o fazer. Tentava-se reduzir ao máximo a circulação de pessoas e com eles o contágio de doenças (Abreu, 2020, p. 55), no sentido de prevenir e reforçar o isolamento (Abreu, 2006, p. 113). As praças públicas e as fontes eram limpas, num esforço conjunto de tornar as cidades mais higienizadas. Também os enterros sofriam alterações, nomeadamente através da colocação dos cadáveres em valas comuns ou em covas mais fundas, para além dos seus bens serem queimados e das suas habitaçóes poderem ser encerradas e tornarem-se objeto de medidas de higiene obrigatórias. Sepulturas com pouca profundidade possibilitavam que animais desenterrassem com facilidade os cadáveres ou parte deles, o que provocava cheiros nauseabundos e potenciava doenças. Podiam ainda ser erigidos hospitais, que funcionavam apenas durante o tempo da peste, aliviando o débil sistema público de saúde. Os núcleos urbanos eram ainda vigiados por forças de segurança, procurando que as medidas fossem cumpridas.

Cidades e vilas fechadas, quarentenas instaladas, cordões sanitários erguidos, medidas de higiene acionadas para ambientes particulares e públicos e suspensão de atividades religiosas, sociais e económicas constituíam as principais medidas para conter os surtos de peste da Idade Moderna.

A peste de 1635 alastrou a diversas regióes do reino, sendo muito sentida em Lisboa, nas Beiras e no Alentejo, regióes de onde saíram muitos pobres tentando escapar à doença e à fome. Dirigiram-se para a capital na tentativa de alcançarem uma esmola mais robusta que lhe garantisse a sobrevivência. Sublinhe-se, aliás, que durante os períodos de peste aumentava a circulação de pobres, apesar de não poderem entrar nas cidades, por causa da fome. Mas o Algarve foi também contaminado, como do outro lado da fronteira aconteceu com Madrid (Rodrigues, 1990, p. 135-136). À fome e à epidemia, juntavam-se também as revoltas populares contra a união ibérica e a sobrecarga de impostos.

Em Braga, durante o tempo de peste, a cidade encheu-se de pobres e de soldados que vagueavam pelas suas ruas, solicitando ajuda. Perante a elevada pobreza, a Misericórdia teve de alterar os critérios de distribuição de esmolas, reduzindo a 
quantidade para alargar a sua ação a mais necessitados (Castro, 2006, p. 61). A instituição procurava responder ao aumento de pobreza, o que acontecia sempre em situação de crise económica e social.

Com o alastramento da doença, gerava-se instabilidade e medo e conheciam-se profundas alterações na vida social e económica. E embora os pobres constituíssem o grupo mais vulnerável, as pestes atacavam todos os grupos sociais e todas as idades. Todos estavam vulneráveis à peste, embora saibamos que o rei e os nobres se afastavam da cidade infetada deslocando-se para locais limpos.

Apesar de não termos notícias de mais pestes nesta década na cidade de Braga, elas continuaram em várias regiões do reino. Em 1637 as cartas que chegavam a Évora idas da Corte eram desinfetadas com vinagre e passadas pelo fogo para as purgar de algum mal contagioso (Abreu, 2014, p. 72).

Passados alguns anos, entre 1647-48, a cidade de Braga foi novamente fustigada por uma peste. A cidade continuava suja, apesar dos esforços da Edilidade, tendo conhecido uma nova vaga de doença em 1650. Estávamos em plena guerra da Restauração e Braga transformara-se num corredor de soldados em direção à fronteira do Minho com a Galiza. Uma vez mais a Câmara mandou varrer as ruas e limpá-las com água todos os dias, medida enérgica e denunciadora da necessidade de combater a sujidade existente (Araújo, 2017, p. 147-167). Esta peste veio num navio de Argel e alastrou por toda a Península Ibérica. Tratou-se de um surto de peste bubónica, doença com alguns dias de incubação, com uma sintomatologia já conhecida, os bobões surgidos em algumas partes do corpo e altamente contagiosa e letal (Snowden, 2020, p. 45-46).

Em 1654, o hospital de S. Marcos denunciava a peste existente na cidade e impunha medidas de higiene no que tocava aos enxergóes em que os doentes se deitavam. Embora a palha dos enxergóes devesse ser renovada várias vezes ao ano para evitar que os parasitas se instalassem nela, assim não acontecia, mas na data assinalada exigia-se esse cumprimento para que 'os males não se peguem de hir para os outros' (ADB, Livro no 706, fl. 29) Havia, por conseguinte, a consciência de que a promiscuidade favorecia a instalação de parasitas e de que a falta de limpeza proporcionava o contágio das doenças. Ainda no quadro da guerra citada, em 1658, quando se agravam as investidas da Espanha contra Portugal, após ficar liberta da guerra com a França, Portugal conhece uma 
nova epidemia e em Lisboa foram muitos os que sucumbiram. O grande Hospital de Todos-os-Santos conheceu o aumento diário de doentes, queixando-se os seus administradores da falta de camas para os deitar e de dinheiro para os prover (Rodrigues, 1990, p. 145). A peste chegou a Braga e na cidade voltaram a ser implementadas medidas de limpeza, ordenadas pelo Município, que impóe retirar as imundices das ruas e a sua limpeza, assim como proibiu a existência de águas estagnadas. Estávamos novamente perante um surto de tifo exantemático, que se prolongou durante o ano seguinte, com incidência particular nos meses de Inverno, embora pudesse aumentar na Primavera. A ele podia agregar-se outras doenças do foro digestivo e respiratório (Rodrigues, 1990, p. 146). Este surto atacou também a vila de Ponte de Lima, tendo disparado o número de mortos sepultados pela Misericórdia local. Refira-se, aliás, ter sido a doença que mais trabalho deu a esta confraria durante toda a Idade Moderna.

Epidemias de tifo foram conhecidas em várias localidades e em diferentes tempos. Vila Viçosa tem também o seu calendário de pestes. E se, no século XVI, foi assolada nas décadas de 20 e 30 por várias delas, em 1569 conheceu também a Grande peste, sendo posteriormente fustigada por várias enfermidades em 1579 e 1580 e em 1590 (Araújo, 2006, p. 31-37). No século seguinte, os anos de 1644, 1676, 1677, 1679 e 1684-1685 foram igualmente tempos difíceis e de acionamento de medidas para combater as pestes.

Quando se conhecia a existência de mal contagioso em alguma localidade próxima, acionavam-se medidas de higienização dos espaços públicos, como acender fogueiras nas ruas e fiscalizar animais para as tentar debelar. No século XVIII, a vila conheceu mais uma epidemia de tifo, em 1763-64, numa altura em que se encontrava cheia de militares. Na Santa Casa da terra vários dos mesários morreram, embora alguns deles tenham escapado, depois de infetados (Araújo, 2000, p. 289-290).

A cidade de Braga conheceu várias pestes, mas infelizmente nem sempre conseguimos muita informação sobre as doenças, os seus efeitos e a forma como as populações lidaram com elas.

No combate aos efeitos das doenças não estiveram apenas ligados os que estavam diretamente associados aos cuidados de saúde, pois também os homens da igreja católica andaram envolvidos. Entre 1684 e 1685 a cidade de Braga viu-se uma vez mais 
a braços com uma nova peste. E a ação dos religiosos de S. Filipe de Néri foi fundamental em termos de assistência espiritual aos que se encontravam no hospital com febres malignas. Estes religiosos recém-instalados no Convento dos Congregados alcançaram grande popularidade como confessores e pregadores, mas neste momento foram fundamentais na ajuda a bem-morrer aos que tinham contraído a peste e estavam internados em S. Marcos (ADB, Congregação do Oratório, Contas (receitas) 1686-1687, fls. 2-2v.). O hospital dispunha na altura de apenas um capelão, que não conseguia vencer tanto trabalho, por isso a ajuda prestada pelos citados religiosos foi preciosa, num tempo em que quando se estava para morrer era o padre que ganhava relevância na cabeceira do moribundo, para o sacramentar, ajudar a aceitar a morte e a resignar-se com o fim da vida (Araújo, 1997, p. 182-183). Em tempo de confessionalização, o hospital estava ao serviço da igreja católica, servindo de local para doutrinar os pobres, como se verificava também no tempo de cura dos portadores de boubas, que recebiam padres para lhes ministrarem rudimentos de doutrina e de exemplos de vida, uma vez que os pobres eram acusados de cuidarem pouco destes aspetos.

Em 1768, a doença visitou novamente a cidade e muitas localidades vizinhas, tendo em Braga provocado efeitos muito nefastos no hospital. Estava, todavia, no começo, mas já os capelães do hospital ${ }^{1}$ se recusavam a celebrar no altar de S. João de Deus, invocando o medo que tinham das doenças que grassavam. No ano seguinte, em outubro, a peste já matava muita gente. De sorte que impotente perante a escalada, em janeiro do ano seguinte, a cidade estava tomada pela peste, o que levou o arcebispo D. Gaspar de Bragança (1758-1789) a ordenar uma procissão solene a S. Sebastião, na qual deviam marcar presença todas as confrarias de Braga. Este santo está associado aos males das pestes, fomes e guerras, sendo considerado seu protetor. A procissão contou com outros intervenientes, tendo marcado presença representantes das diversas casas religiosas masculinas, mas também clérigos seculares e o Cabido. Atrás, no pálio, seguia o arcebispo. O autor do Livro Curioso descreve com pormenor a peste que grassou em 1770, fornecendo informação muito valiosa. A procissão visava implorar ao santo que

\footnotetext{
1 Os cinco capelães no coro da igreja do hospital datam de 1688, instituídos pelo cónego João de Meira Carrilho, que tinham também como obrigação ajudar a bem morrer os internados e a celebrar nos altares do complexo hospitalar para os doentes, sendo seis os religiosos que os assistiam espiritualmente.
} 
a cidade fosse liberta das graves febres e enfermidades que nela andavam, provocando a morte de muita gente ao mesmo tempo que se devia pedir perdão a Deus pelos pecados cometidos. Nela, estiveram presentes as maiores individualidades religiosas da cidade, bem como o seu restante aparelho religioso: confrarias, ordens religiosas e clero secular. $\mathrm{O}$ assunto era muito grave, dizia respeito a todos e todos deviam agir no sentido de o minimizar, implorando junto do santo protetor. Desconhecemos quantas confrarias desfilaram na procissão e que ordens religiosas também o fizeram, mas, em 1764, existiam na cidade mais de sete dezenas de irmandades (Gomes, 2002, p. 132).

O cronista refere o elevado contágio da doença, mas não a identifica, mencionando que em casa em que entrasse ninguém escapava, provocando elevada mortandade. Esta peste não se sentiu apenas em Braga, todo o reino a conheceu.

A cerimónia religiosa iniciou-se com um sermão para depois ser iniciada a referida procissão, a qual saiu da Sé, como normalmente acontecia em ocasióes importantes e depois de descer pela rua Nova subiu as Carvalheiras passando em frente à capela de S. Sebastião, alcançou a rua do Alcaide, acedeu à rua de S. Marcos, Fonte da Carcova, campo da Vinha e entrou novamente na rua Nova para regressar à Sé (Livro Curioso, 2020, p. 143). O circuito alargou-se a uma parte nobre da cidade, passando o desfile em frente da capela do santo homenageado.

Entretanto, a peste deve ter abrandado, uma vez que a semana santa decorreu sem anomalias, tendo contado com o Descendimento da Cruz feito na igreja de Santa Cruz e as cerimónias do enterro do Senhor. Porém, uma nova vaga da doença regressou em força no mês de maio, provocando efeitos vários na população da cidade. Andava a gente como pasmada com a intensidade da peste caracterizada por uma subida das enfermidades, com febres contagiosas, apegadiças e sumárias. Sem poder conter as doenças, a população espantava-se e estava em desassossego com a sua intensidade e gravidade, por serem de fácil contágio e muito mortíferas. Era o espanto e o medo que dominava as pessoas, porque não podiam dominar a doença ${ }^{2}$. Tanto mais que depois de serem por ela tocados, a média de duração de vida era de 14 dias, ou menos, e poucos

\footnotetext{
2 Existia desde a Idade Média um hospital para velhos na cidade, que não estava dotado de corpo clínico. Situado em S. Tiago, era ocupado por gente pobre, que nele não dispunha de cuidados de saúde.
} 
lhe escapavam. Entre outubro de 1769 e maio de 1770 estima-se que tenham morrido mais de 1230 pessoas (Livro Curioso, 2020, p. 144), o que é realmente um número muito elevado se tivermos em consideração que Braga teria cerca de 17 mil habitantes, ou seja, cerca de 6,7\% da sua população foi dizimada por esta peste.

Tratando-se de um assunto da maior importância, os serviços públicos de saúde eram chamados para ajudar na resposta ao problema. Único hospital da cidade, $S$. Marcos, administrado pela Misericórdia desde 1559, teve nesta peste como em outros momentos de várias epidemias na cidade um papel de grande relevo. Embora integrado na malha urbana, o hospital sempre que podia procurava preservar-se das epidemias para que a população internada não sofresse o contágio de outras doenças que grassavam com muita gravidade. Assim, quando era declarada peste na cidade, esta unidade de tratamento tomava de imediato medidas para aumentar a higiene dentro de portas e nas suas imediaçôes. Nos locais circunvizinhos era reforçada a limpeza das ruas para que se mantivesse um espaço de segurança entre o aglomerado populacional e o hospital. Procurava também melhorar os serviços que oferecia e que o espaço infetado não lhes chegasse. Era para disponibilizar melhores espaços e serviços que se tomavam as citadas medidas. No século XVIII, este hospital conheceu obras de remodelação, que o dotaram não somente de novos espaços, como aconteceu com o claustro, como hoje o conhecemos, como alargou a sua área de internamento, mas também as enfermarias da convalescença e a cozinha. Ao longo de todo o século foi objeto de programas de reforma, onde trabalharam alguns homens de nomeada. Referimo-nos a Manuel Pinto de Vilalobos, engenheiro militar e, no final do século, ao arquiteto Carlos Amarante.

Devido a esta peste, em maio de 1770, o hospital estava cheio de doentes. Eram tantos que extravasaram as enfermarias, sendo colocados também nos corredores e noutros espaços livres onde era possível alocar mais uma cama ou uma esteira. Todos os locais onde era possível colocar camas foram usados para esse fim, estando deitados dois doentes em cada leito. Esta forma de os receber não seria a mais indicada, mas foi a única encontrada para fazer face à epidemia. A mortalidade era grande, chegando a elevar-se a seis doentes por dia, o que se reconhece ser muito forte (Livro Curioso, 2020, p. 144). Mas não morreram apenas os que chegavam para ser internados, como o contágio era grande, também enfermeiros, enfermeiras e capelães ficaram doentes e 
faleceram. O mesmo aconteceu com os mordomos, ou seja, os mesários encarregues de acompanhar a vida hospitalar que sucumbiram igualmente perante a doença. Os que conviviam de perto com os infetados, para os servir material e espiritualmente estavam vulneráveis, foram contaminados e levaram a doença para outros espaços, nomeadamente para suas casas. A situação do hospital complicou-se não somente por estar sobrelotado, mas também por não existir quem o quisesse servir, substituindo os assalariados mortos. Todos tinham medo e se antes havia vários candidatos para uma vaga, como acontecia sempre que vagava um lugar no setor da enfermagem, perante a epidemia não surgia ninguém.

Nestas ocasióes, as medidas de higiene eram redobradas e em S. Marcos procurou-se acabar com as alcovas por serem consideradas prejudiciais, uma vez que se desejava abrir espaços mais arejados onde o odor dos corpos e também dos tratamentos se dissipasse. Todavia, foi preciso esperar mais tempo para que as alcovas desaparecessem deste hospital. Mas as enfermarias foram alvo de maiores cuidados. A colocação de ervas aromáticas, como o alecrim, a passagem da enfermeira com brasas para as defumar antes dos médicos e cirurgiões entrarem, visavam criar ambientes mais arejados e mais purificados. Cuidados redobrados eram igualmente tidos com a roupa.

O medo estava instalado na cidade e não apenas no hospital. Também nas casas particulares, os que contraíam a doença não eram visitados por familiares e amigos, devido à rápida contaminação. Perante a situação e quase doidos, os habitantes da cidade recorreram novamente ao arcebispo no sentido de serem realizadas preces para aplacar a ira e moderar as enfermidades. Entendida como um castigo divino, a doença devia ser acompanhada de oraçôes para contar com a compaixão de Deus. O arcebispo ordenou a vinda da imagem do Bom Jesus do Monte, a qual foi colocada na igreja de S. Vítor, tendo-se-lhe começado a fazer preces. Estas foram reforçadas com uma novena que se iniciou no dia 12 de maio, tendo o prelado ordenado a todas as confrarias que orassem umas na citada igreja e outras na capela de S. Sebastião durante os nove dias. A cerimónia revestia-se de um ritual, que a trazia para o exterior. Cada participante saía de sua casa para se integrar na sua confraria, caminhando cantando a ladainha dos santos até à igreja para onde se deslocava e o mesmo acontecia no regresso. A cidade enchia-se de súplicas através do canto e da oração, envolvendo todos os que participavam e assistiam. 
E causava ternura, o ver ir umas cantando para lá, outras encontrando-se para cá, todas entoando a dita ladainha em voz baixa e entoada (Livro Curioso, 2020, p. 144). O costume de rezar em voz alta estava instalado na cidade e fazia parte das práticas de algumas confrarias. As de Nossa Senhora do Rosário, culto reforçado em Trento, desenvolviam práticas de oração comunitária ao cair da noite, rezando o terço em voz alta por algumas artérias da cidade e envolvendo os crentes que desejassem participar. Esta forma de integração dos fiéis em práticas coletivas insere-se nos ideais da Contrarreforma e procurou o envolvimento de todos em momentos de especial relevo para a igreja católica (Marques, 2000, p. 611-614). Durante a novena, quando passavam as irmandades com os seus fiéis os sinos das igrejas e capelas bamboavam, publicitando a cerimónia e chamando ainda os interessados em participar.

Mas a imagem do Bom Jesus do Monte não foi a única a deslocar-se para a cidade. Também a de Santa Maria Madalena, do monte da Falperra veio para a igreja de São Vicente, onde de igual forma se fizeram preces com o mesmo objetivo. Esta imagem de Santa Maria Madalena era muito requisitada na cidade para se fazerem procissóes rogativas, sempre que havia um motivo muito ponderoso que precisava da ajuda do divino. Mau tempo, secas e doenças levavam à deslocação da imagem e dos crentes para os espaços públicos e as igrejas onde imploravam pela alteração da situação. $\mathrm{O}$ mesmo se verifica noutras localidades, onde os fiéis se serviam das imagens de santos que consideravam muito milagrosas para se manifestarem e implorarem proteção divina (Silva, 2019, p. 202-213).

A novena da igreja de S. Vítor foi replicada noutras igrejas e capelas da cidade. No mesmo dia 12 de maio iniciaram-se mais novenas a S. Sebastião, S. Roque e a Santo António do campo dos Touros, nos respetivos locais de culto. A Sé também se associou às preces, rezando-se na principal igreja da cidade pelo fim das enfermidades. Aqui, desceram-se dos altares as imagens de Nossa Senhora das Angústias e de Nosso Senhor da Agonia e na presença de todo o Cabido e de todos clérigos da freguesia da Sé, assim como as confrarias desta igreja, fizeram-se preces (Livro Curioso, 2020, p. 145). Estas cerimónias eram normalmente organizadas pela Mitra, mas em tempo de Sé Vacante a Câmara assumiu a sua realização. Também a Misericórdia da cidade as promoveu sempre que considerou necessário. 
Como se constata, em muitas igrejas e capelas, a oração intensificou-se e os fiéis foram chamados a mais manifestações religiosas, no sentido de alcançarem as graças que desejavam. E nas comunidades religiosas não somente se orava, mas também se fizeram disciplinas, mortificando o corpo. Em simultâneo, surgiu uma oração dedicada especialmente à situação em que a cidade se encontrava e que em outros tempos tinha sido utilizada em Roma em contexto da mesma epidemia. A oração, inscrita num pergaminho, depois de benzida pelos clérigos antes e no fim das missas, era atada no braço esquerdo, acompanhando cada um que a levava para poder ser lida quando necessário. A oração integrava várias letras descritas pelo cronista, o qual realça a fé de quem a usava e o livro onde se encontrava a explicação das letras (Livro Curioso, 2020, p. 145).

Tempo de muita confusão, a peste de finais de 1769 e 1770 colocou a cidade em polvorosa e clamou pela interceção divina, numa clara evidência da incapacidade da ciência responder à epidemia que grassava na cidade.

Perante o surto, o hospital teve de fazer mudanças, uma vez que os doentes eram em número muito elevado. Como para os que não morriam não existia local para os continuar a tratar porque as camas eram necessárias, mas também não deviam ser enviados para casa sem estarem totalmente restabelecidos, em 1770, S. Marcos decidiu construir novas enfermarias para convalescentes. Para este projeto recebeu um importante legado de João Duarte de Faria, no valor de 400 mil réis, deixado no seu testamento e destinado a avançar com a obra em curso, situada no primeiro andar (ADB, no 17 , fls. 66-66v.). A entrega do dinheiro ocorreu em agosto de 1770, já depois do surto ter alcançado o seu pico.

Por esta altura, Braga era uma cidade caracterizada ainda por uma forte marca rural, mas também por um significativo dinamismo comercial local, onde abundavam lojas de porta aberta com variados produtos à venda (Capela, 1991, p. 54). Mas para além dos habitantes da cidade e dos que a ela se deslocavam por diversos motivos, ao hospital acorriam doentes de toda a diocese, o que num século em que o corpo ganhou espaço à alma, os que o procuravam cresceram em grande número.

De volta, em 1784, a doença epidémica colocou novamente a cidade em estádio de sítio, devido a um surto de tuberculose. Os ecos fizeram-se sentir no hospital, de tal 
forma que o obrigaram a criar um espaço especialmente destinado aos seus portadores. Impunha-se a separação dos restantes doentes devido ao célere contágio. Todavia, o medo era tanto, que nem médicos nem enfermeiros queriam tratar esses doentes, o que levou o médico Simão Ferreira a ser expulso por se recusar e assisti-los. Mas não estava só, pois no ano anterior o enfermeiro Geraldo Ferreira alegou ser-lhe custoso tratar das doenças contagiosas existentes no hospital, como era a tísica e outras, tendo solicitado dispensa para se dedicar somente aos restantes internados. O seu pedido levou a que os doentes com enfermidades contagiosas ficassem ao cuidado do hospitaleiro João Ferreira (ADB, Livro no 16, Als. 455v., 465). Sem médico para os tratar e com o enfermeiro dispensado também de o fazer, os tuberculosos ficaram ao cuidado apenas do hospitaleiro. Com um número cada vez maior destes doentes, o hospital criou uma enfermaria apenas para eles, retirando-os do ambiente de internamento dos restantes enfermos. $\mathrm{O}$ temor que a tuberculose infundia nas pessoas era muito grande, levando a que muitos hospitais se recusassem a receber os seus portadores. A doença já no século XVII se abateu sobre muita gente e na centúria seguinte, algumas cidades fundaram hospitais para estes doentes, como se verificou, por exemplo, em Sevilha (Carmona García, 1997, p. 350).

Em 1797 abateu-se uma vez mais uma epidemia sobre Braga, atingindo algumas das suas instituições com severidade. O colégio de São Caetano, fundado poucos anos antes pelo arcebispo D. Frei Caetano Brandão (1790-1805) e destinado ao internamento de rapazes órfã̃os, foi um dos exemplos. Muitas das suas crianças foram contagiadas e várias delas sucumbiram à doença, assim como o irmão enfermeiro da dita instituição (Abreu, 1997, p. 165). Como o arcebispo fundador visitava frequentemente o colégio, acabou também por ser contaminado, embora se tenha salvo. Todavia, as mortes na cidade foram em número muito elevado, arrastando gente de todos os grupos sociais (Peixoto, 1992, p. 246-247). Sublinhe-se que esta foi a crise mais severa em Braga em termos de mortes hospitalares da Idade Moderna. O hospital de S. Marcos registou para este ano o número mais elevado de mortes em quase 250 anos sob a administração da Misericórdia (Araújo, 2014, p. 49).

De tal forma, as pessoas estavam em sobressalto com a situação, que uma vez mais recorreram ao sagrado, implorando ajuda. As confrarias da cidade desempenharam um papel muito relevante na convocação dos fiéis à oração, fazendo preces 
coletivas e procissóes com as imagens dos santos padroeiros e outras (Peixoto, 1992, p. 95). Santa Maria Madalena do Monte da Falperra foi também convocada, descendo à cidade para se juntar às orações e a outras manifestaçôes religiosas. O memoralista Inácio José Peixoto recorda ainda a desconfiança que se instalou entre a população da cidade, reportando-se a uma situação de pânico em que todos viviam (Peixoto, 1992, p. 49). Associada a esta crise epidémica esteve uma elevada subida do custo de vida. O preço dos cereais e de outros produtos alimentares subiu muito, colocando graves entraves à maioria da população por não lhes conseguir aceder. Como os cereais continuavam a ser a base alimentar das pessoas, não os poder comprar por falta de recursos significava aumentar as possibilidades de contrair a doença, por debilidade alimentar. A isto juntava-se a falta de condiçôes de higiene e outras carências associadas às condições de habitação. Estes fatores perturbavam a sazonalidade da morte própria do Antigo Regime (Rodrigues, 1990, p. 80). De tudo isto padeciam os pobres e as instituiçóes de caridade. O hospital de S. Marcos foi auxiliado nesta fase como noutras pelo arcebispo de cidade, que o visitava com frequência, deixando esmolas aos que nele estavam internados para minimizar a situação em que se encontravam.

Mas a peste permaneceu ao longo de mais dois anos, com diversas vagas. Entre 1797 e 1799, a cidade foi várias vezes flagelada pela epidemia, causando efeitos devastadores nos seus moradores. Durante este período a Edilidade uma vez mais exigiu a limpeza das ruas e das casas insalubres, ordenando que as suas frontarias fossem limpas e caiadas, o que se verificava também em algumas cidades europeias no mesmo período (Pérez Álvarez, 2009, p. 359-361).

Apesar dos surtos epidémicos que surgiram nesta centúria, as taxas de mortalidade poderiam ter sido muito mais elevadas se os índices de imunidade não tivessem crescido. Quem fosse tocado pela doença e não morresse ficava imune. Num período em que os avanços médicos se iam fazendo a custo, a imunidade terá sido fundamental para que a mortalidade não atingisse cifras mais elevadas. Todavia, foi também neste século que começaram a surgir as primeiras vacinas para a varíola, doença que atacava muito as crianças (Vigarello, 1999, p. 142-143). Em Portugal começaram também a ser inoculadas, mas a população resistia com medo, tendo alguns profissionais de saúde desenvolvido um trabalho notável junto das populaçôes (Fernandes, 2016, p. 187-188). 
Foi ainda nesta centúria que se conheceu o importante contributo do movimento higienista, expresso nos cuidados postos na saúde pública, diretamente associado à saúde das populaçóes (Porter; Vigarello, 2005, p. 323-357).

Com reflexos nos hospitais, estas medidas foram sendo introduzidas de forma paulatina, criando melhores condições de salubridade aos doentes. Em S. Marcos, maiores cuidados de higiene eram reclamados pelos profissionais de saúde, designadamente pelos médicos e cirurgióes, que mantinham vigilância apertada sobre os restantes colaboradores, exigindo roupa bem lavada e denunciando a negritude com que esta chegava às enfermarias, assim como maiores cuidados na higiene corporal dos doentes e dos espaços. Os enfermeiros e hospitaleiros foram também visados, exigindo-se-lhes maior cuidado com a higiene corporal dos internados, maior conforto nas enfermarias, mais limpeza no claustro e nos corredores, maiores cuidados na alimentação, etc. Também às lavadeiras se impunham regras para o cumprimento na apresentação das roupas e principalmente nos cuidados postos na sua lavagem. Estas preocupaçóes ecoavam na forma como a Misericórdia entendia os cuidados hospitalares e os reflexos das novas políticas higienistas no hospital. Em finais do século XVIII, o edifício do hospital era caiado duas vezes ao ano, tendo-se em vista os cuidados de limpeza e a sua apresentação.

\section{NOTAS FINAIS}

As breves notas que deixamos sobre as pestes em Braga procuram trazer para os dias de hoje situaçóes de epidemias e mortes ao longo dos três séculos da Idade Moderna. Neste esforço de memória, realçamos as condiçôes de insalubridade da cidade, que não constituíam uma particularidade sua, antes se mantinham presentes em todas as cidades europeias, sublinhamos as débeis condições de higiene existentes, principalmente junto dos grupos sociais mais desfavorecidos, onde a doença encontrava maiores condiçôes de desenvolvimento; recordamos as medidas implementadas pelas autoridades locais para promover a limpeza da cidade e dos seus habitantes e conferimos particular atenção ao único hospital da cidade. No âmbito destas medidas, recordamos a higienização dos espaços públicos, a proibição da sujidade, o encerramento das cidades e vilas, através das suas portas e postigos, os cordóes sanitários, as quarentenas, as multas para os infratores e o medo. O medo sempre presente, que pasmava as populaçóes, 
por se sentirem incapazes de combater a doença, numa altura em que a medicina não respondia às necessidades sentidas por todos e as enfermidades matavam de forma sumária. Todavia, apesar desta situação, as epidemias atingiam principalmente os grupos sociais mais humildes, agravando as diferenças sociais. Recordamos as principais doenças e os seus efeitos na vida económica e social e principalmente em termos demográficos, originando crises de mortalidade sem precedentes. Demos ainda particular realce ao hospital e à forma como a cidade viveu algumas destas pestes, nomeadamente nos séculos XVII e XVIII, convocando o sagrado na tentativa de as aplacar. Era altura de trazer para a praça pública todo o aparelho religioso da cidade, numa demonstração de força e de unidade perante uma tragédia que os humanos não conseguiam vencer. Missas, procissões, orações, novenas, cânticos, padres, crentes e sinos a tocar davam corpo a um universo mental que buscava no sagrado a solução para o gravíssimo problema das pestes. A par destas manifestações, o século XVIII é portador de algumas mudanças em termos de medicina, augurando significativas alterações na centúria seguinte, pese embora a recorrente permanência das epidemias.

\section{FONTES MANUSCRITAS}

Arquivo Distrital de Braga (ADB).

Fundo da Misericórdia.

Livro dos Termos ou actas 1758-1769, № 16 .

Livro dos Termos ou actas, 1769-1776, no 17.

Livro das visitasoins do Ospital e Beatas e da Casa e Termo dela 1639-1684, oo 706.

\section{FUNDO MONÁSTICO-CONVENTUAL}

Congregação do Oratório, Contas (receitas) 1686-1687.

\section{FONTES IMPRESSAS}

Arrais, D. M. (1633). Do Methodo de conhecer e curar o morbo gallico: propoemse diffinitivamente a essencia, specias, causas, sinais, pronosticco e cura de todos os affectos gallicos e largamente se trata do azougue, salsa parrilha, guayção, pao santo, raiz da China e todos os mais remedios della e infermidades. Lisboa: Antonio Craesbeeck de Mello Impressor de S. A. 
Autor desconhecido (2020), Livro Curioso. Braga: Arquivo Distrital de Braga, Câmara Municipal de Braga.

Oliveira, E. F. (1904). Elementos para a história do município de Lisboa. Tomo XIV. Lisboa: Typographia Universal.

Peixoto, I. J. (1992). Memórias Particulares. Braga: Arquivo Distrital de Braga.

\section{REFERÊNCIAS BIBLIOGRÁFICAS:}

Abreu, J. L. N. (2019). Para evitar os achaques e preservar a saúde: a divulgação da medicina e o "regime de viver” em Portugal- século XVIII. In M. Dillman, F. Ripe (Orgs). Cuidados com o corpo e a alma na LusoAmérica dos séculos XVII a XIX. Pelotas: Universidade Federal de Pelotas.

Abreu, J. L. N. (2010). Higiene e conservação da saúde no pensamento médico luso brasileiro do século XVIII. Asclepio, vol. LXII, no $1.225-250$.

Abreu, J. P. (1997). Em Braga desde 1790 a 1805. D. Frei Caetano Brandão: o reformador contestado. Braga: Universidade Católica Portuguesa, Faculdade de Teologia de Braga, Cabido Metropolitano e Primacial de Braga.

Abreu, L. (2020). O combate aos surtos na Idade Moderna. Visão História, no 50, abril, 54-57.

Abreu, L. (2014). O poder e os pobres. As dinâmicas politicas e sociais da pobreza e da assistência em Portugal (Séculos XVI-XVIII). Lisboa: Gradiva.

Abreu, L. (2006). The city in time of plague: preventive and eradication measures against epidemic outbreaks in Evora bethween 1579 and 1637. Popolazione e Storia, 2, 109-125.

Araújo, A. C. (1997). A Morte em Lisboa. Atitudes e representações 1700-1830. Lisboa: Editorial Presença.

Araújo, M. M. L. (2017). O hospital e a cidade: São Marcos da Misericórdia de Braga (séculos XVII-XIX). In A. P. Korndorfer, C. E. Brum, D. S. Rossi, Daiane, E. C. D. Fleck, E. R. Quevedo (Coords.). História da Assistência à saúde e à Pobreza. Olhares sobre suas instituições e seus atores. São Leopoldo- Brasil: Oikos, 147-167.

Araújo, M. M. L. (2014). Memória e quotidiano: as visitas e as devassas ao hospital de S. Marcos de Braga na Idade Moderna. Braga: Santa Casa da Misericórdia de Braga.

Araújo, M. M. L. (2006). As pestes quinhentistas em Vila Viçosa. Calipolle, no 14, 31-37.

Araújo, M. M. L (2000). Dar aos pobres e emprestar a Deus: as Misericórdias de Vila Viçosa e Ponte de Lima (séculos XVI-XVIII). Barcelos: Santa Casa da Misericórdia de Vila Viçosa; Santa Casa da Misericórdia de Ponte de Lima.

Arrizabalaga, J. (1995-1996). Enfermedad y rearme "moral” en la Europa de finales del siglo XV: las primeras percepciones del “mal frances” en Ferrara. Acta historica et archeologica mediaevalia, nos 16-17, 125-142.

Beirante, M. Â (1994-1995). A gafaria de Évora. A cidade de Évora, noss 2, 1, 213-228. 
Beirante, M. Â. (2008). A gafaria de Évora. O Ar da cidade. Ensaios de história medieval e moderna. Lisboa: Ediçóes Colibri, 235-251.

Braga, I. D. (2001). Assistência, saúde pública e prática médica em Portugal. Séculos XVI-XIX. Lisboa: Universitária Editora.

Carmona García J. I. (2000). Crónica urbana del malvivir (s. XIV-XVIII). Insalubridad, desamparo y ambre en Sevilla. Sevilla: Universidad de Sevilla.

Carmona García, J. I. (1997). El sistema de la hospitalidad pública en Sevilla del Antiguo Régimen. Sevilla: Diputación Provincial de Sevilla.

Capela, J. V. E. (1991). O Município de Braga de 1750 a 1834. O governo e a administração económica e financeira. Braga: Câmara Municipal.

Castro, M. F. (2006). A Misericórdia de Braga. Assistência material e espiritural. Braga: Santa Casa da Misericórdia de Braga.

Fernandes, P. S. C. (2016). O hospital e a Botica da Misericórdia de Penafiel. 1600-1850. Penafiel: Santa Casa da Misericórdia de Penafiel.

Gomes, P. A. C. S. (2002). Oficiais e confrades em Braga no tempo de Pombal. (Contributos para o estudo do movimento e organização confraternal bracarense no século XVIII)(dis. de Mestrado policopiada). Universidade do Minho, Braga.

Jutte, R. (1996). Syphilis and confinement. In D. Junker, S. D. Mattern (Eds). Institutions of confinement: hospitals, asylums and prisions in Western Europe and North America 1500-1950. Cambridge: University Press.

Le Goff, J. (1985). As doenças têm história. Lisboa: Terramar.

Marques, J. F. (2000). Orações e Devoçôes. In C. M. Azevedo (Dir.). História Religiosa de Portugal, vol. II. Lisboa: Círculo de Leitores, 603-669.

Oliveira, A. (2015). Capitulos da História de Portugal, vol III. Viseu: Palimage Editores.

Pardal, R. (2007). As elites de Évora ao tempo da dominação Filipina. Estratégias de controlo do poder local (1580-1640). Lisboa: Edições Colibri/CIDEHUS.

Pérez Álvarez, M. J. (2009). Insalubridad y respuesta institucional en la ciudad de León en el siglo XVIII. In O. Rey Castelao, R. J. López (Eds.). El mundo urbano en el siglo de la Ilustración, II. Santiago de Compostela: Xunta de Galicia, 357-371.

Porter, R. Vigarello, G. (2005). Cuerpo,s alud y enfermedades. In A. Corbin, J. J. Courtine, Vigarello, G. Historia del cuerpo. Del Renacimiento a la Ilustración. Madrid: Taurus Historia, 323-357. 
Rawcliffe, C. (2001). Learning to love the Leper: aspects of institutional charity. Anglo-Norman England. Anglo Norman Studies, 23, 241-254.

Rodrigues, T. (1990). Crises de mortalidade em Lisboa, séculos XVI e XVII. Lisboa: Livros Horizonte.

Silva, L. P. (2019), Oclima no Noroeste de Portugal(1600-1855): dos discursos aos impactos (tese de doutoramento policopiada). Faculdade de Letras da Universidade do Porto, Porto.

Snowden, F. M. (2020). Epidemics and Society from the black death to the present. Yale: University Press.

Tinoco, I. W. S. (2016). Por uma história dos leprosos em Portugal pata além da lepra (sécs. XIII-XV), (dis. de Mestrado policopiada). Universidade Federal do Rio de Janeiro, Rio de Janeiro.

Vigarello, G. (1999). Histoire des pratiques de santé. Le sain et de malsain depuis de Moyen Âge. Paris: Éditions du Seuil. 